\title{
From auditory image to auditory percept: Facilitation through common processes?
}

\author{
GEORGE P. STUART and DYLAN M. JONES \\ University of Wales College of Cardiff, Cardiff, Wales
}

\begin{abstract}
Two experiments explored implicit memory for auditory stimuli as measured by a test of perceptual identification. The facilitative effect of perceived auditory primes was contrasted with that of imaged auditory primes. In Experiment 1, there was a significant priming effect from imaged spoken-word primes that did not differ significantly from the level of priming due to perceived spoken-word primes, measured by a test of auditory perceptual identification. There was no facilitation of spoken-word identification following creation of an image of a word's referent sound. In Experiment 2, identification of an environmental sound was facilitated by prior processing of an imaged sound from the same category, though there was significantly more transfer following processing of the actual sound.
\end{abstract}

Implicit memory is a reflection of the degree to which the processing of a stimulus can improve subsequent performance in the identification or recovery of a related stimulus. Unlike explicit memory, implicit memory is thought to occur without conscious recollection of the study episode (Richardson-Klavehn, Gardiner, \& Java, 1994; Schacter, Bowers, \& Booker, 1989). A typical implicit memory paradigm can be divided into two stages: In the encoding stage, participants are presented with a list of materials about which they are asked to make some form of judgment. This is followed by a test phase in which the participants attempt to recover a series of perceptually degraded items, some of which were presented during the encoding phase. Facilitation in the efficiency with which participants are able to identify stimuli that have been processed in the encoding phase, as compared to their efficiency in identifying new stimuli, is taken as an index of the action of implicit memory.

Several theoretical explanations have been advanced for the facilitation effect, but the most popular of these in the discipline of cognitive psychology has been the transfer appropriate processing (TAP) approach (Kolers \& Roediger, 1984; Roediger, 1990; Roediger \& Srinivas, 1993; Roediger, Weldon, \& Challis, 1989). When applied to an implicit memory paradigm, this approach leads to the prediction that the greater the overlap in processes between encoding and test, the more facilitation there will be in the test phase task performance. In such a framework, there is an important distinction between those tests of implicit memory that are said to be data driven and those that are conceptually driven (Roediger, 1990; Roediger et al., 1989; Roediger \& Srinivas, 1993). Facilitation in a data-driven test would be maximized by encouraging the participant to focus on the surface features of the stimulus during the en-

This work was supported by an Engineering and Physical Sciences Research Council studentship awarded to G.P.S. Correspondence should be addressed to G. P. Stuart, Department of Psychology, University of York, Heslington, York YO1 5DD, England (e-mail:gps1@unix.york.ac.uk). coding phase. Conversely, optimal performance in a conceptually driven task would occur when participants were asked to engage in semantic processing of the stimuli during the encoding phase. For this reason, it would be expected that the processing of a written word in a data-driven test would be facilitated to a greater extent after processing of the same word in written form than it would be after presentation of the same word in spoken form. That there is sometimes some cross-modal facilitation has been explained by recourse to the common process of lexical access (Weldon \& Jackson-Barrett, 1993).

If facilitation were to be demonstrated in a data-driven task, it would follow that participants had processed the perceptual features of the experimental stimuli. It is here that an obvious difficulty arises, since an image, by definition, has no "perceptual" features. Direct facilitation of the identification of a percept from an imaginal prime has already been demonstrated by Roediger and Blaxton (1987): Participants were presented with either spoken or written words during an encoding phase and were asked to solve a word fragment completion task in the test phase. Performace on the word fragment completion task was significantly facilitated when participants had created a visual image from a spoken word, as opposed to when they had been given no imaging instructions. In a more recent experiment by Roediger, Weldon, Stadler, and Riegler (1992), participants were presented with a series of pictures and printed words under either graphemic (letter counting) or semantic (pleasantness rating) processing instructions. When a picture was presented in the graphemic processing condition, participants were instructed first to create a visual image of the noun that would label the stimulus. Pictures that had been encoded graphemically produced more priming in both the word fragment and word stem completion tasks than did semantically encoded pictures. In the words of Roediger et al. (1992), formation of a visual image had apparently "engaged central perceptual processes that are used in actually reading the word, so that greater priming occurred in the graphemic condition" (p. 1263). 
If, as suggested by the TAP literature, conceptual processing influences only conceptually driven implicit tests, and given that imaginal and perceptual primes appear to be processed similarly, one would expect little or no "crossform" priming between an image and a percept in a datadriven test. This could be verified by asking participants to form an imaginal prime that was related semantically, but not perceptually, to the probe. In at least three experiments, this has been achieved by asking participants to image the visual referent of a visually presented word (Basden, Bonilla-Meeks, \& Basden, 1994; Blaxton, 1989; Durgunoğlu \& Roediger, 1987). In all three experiments, participants then performed a word fragment completion test that contained some of the encoded words in an alternative visual word form. According to Blaxton (1989), imaging the visual referent is a conceptually driven process, and therefore "does not aid in the processing of physical features of the stimulus word itself ... and so is not predicted to differentially affect data driven task performance" (p. 664). In the study conducted by Durgunoğlu and Roediger (1987), Spanish-English bilinguals were presented with printed lists of English and Spanish words. In one of the conditions, words were presented in Spanish and participants were required to form an image of the word's referent. Performance in a subsequent word fragment completion task was significantly facilitated by visually presented English primes, but performance in the visually presented Spanish and the image-prime conditions was not significantly better than that in the control condition.

Unfortunately, the status of referent-image primes is not clear-cut. In a replication of the experiment by Durgunoğlu and Roediger (1987), Basden et al. (1994) did find a significant priming effect from the imaged visual referent of a Spanish word. They suggested that the greater power of their experiment ( 25 as opposed to the 12 participants used by Durgunoğlu \& Roediger, 1987) may have been responsible for the discrepancy. That there may be a very weak, but significant, facilitation effect from referentimage primes finds further support in an experiment by Blaxton (1989, Experiment 3). Participants were presented with sets of words printed in one of two fonts. For half of the words, participants were asked to form an image of the referent. When the participants were presented with a word fragment completion test, primes in both fonts produced a significant level of facilitation. Although there was no main effect of imagery, there was an interaction between imagery, test typography, and study typography that occurred because, in the absence of any instructions to image, there was an advantage for test stimuli that had been presented using the same font in the study and test phases. When participants were asked to form an image of the word's referent, there was no effect of changing font between study and test.

\section{NONVERBAL SOUNDS AND NONVERBAL IMAGES}

Because the TAP approach emphasizes an overlap in processing between the two stages of an implicit memory test, there is no need to assign special status to spoken or written words. For this reason, the priming of nonverbal stimuli such as pictorially represented objects (Snodgrass \& Hirsham, 1994; Weldon \& Jackson-Barrett, 1993) or environmental sounds (Stuart \& Jones, 1995) can easily be accommodated. According to the TAP approach, there is no reason to expect that facilitation from an image would be restricted to the visual-verbal modality. Until now, however, there has been no systematic attempt to explore facilitation from images in other modalities or stimulus forms. Furthermore, there do not appear to be any reports of an implicit memory paradigm having been used. Some experiments in the imagery literature indicate the possibility of an interaction between nonverbal images and percepts. For example, some evidence in the auditory modality suggests that creating an auditory image of a pure tone can facilitate detection of a "real" tone (Farah \& Smith, 1983; Okada \& Matsuoka, 1992). Similarly, in the visual modality, participants' performance at detecting pictures embedded in visual noise in a two-alternative forced choice was significantly improved after creation of a consistent visual image (Peterson \& Graham, 1974). The available evidence thus suggests that the facilitatory effect of an image is not limited to verbal-perceptual identification. A conclusion common to many of the experiments reported above is that images can in some way interact with percepts. In the following experiments, this interaction within the auditory modality was investigated further, using both verbal and nonverbal stimuli.

\section{EXPERIMENT 1}

A potential problem with many imaginal prime experiments is that presentation of the imagery or no-imagery instructions has been a within-subject factor. Even with complete counterbalancing, it is difficult to be sure that participants who have been presented with the imagery condition first were not unintentionally creating images in the no-image condition. Rather than relying on postexperimental questionnaires to determine that participants had not experienced images in the no-image condition, we adopted a between-subjects design for Experiment 1 .

Three between-subjects groups were asked to identify sets of stimulus items. Each item was represented in one of four forms: written word, spoken word, written auditory scene description, and nonverbal sound. The encoding phase format of some of the stimuli was consistent between participant groups and differed for others. Each participant group was given a different set of encoding phase instructions. All three groups were then given the same perceptual identification test phase, which involved the identification of auditorily degraded spoken words. In order to examine the facilitatory effect of imaged spoken words, members of one of the participant groups were asked to create a spoken image of a word that had been presented to them visually. Also of interest was the effect of imaging an auditory stimulus in one form on the identification of the stimulus in an alternative form. This was accomplished by presenting participants with a printed 
noun and asking them to imagine that they were able to hear the sound produced by the referent of that word. In order to provide some baseline performance levels for the facilitation effect, conditions in which participants heard a spoken word, heard an environmental sound, or simply read (without imaging) a printed word were also included. Finally, for the sake of balancing the design, a baseline condition was included in which participants were asked to identify the sound-producing object from a written description of an auditory scene, which consisted of two short sentences.

Method
Subjects
Seventy-two University of Wales College of Cardiff undergradu-
ate volunteers participated in this experiment. All spoke English as
their first language and all reported normal hearing. Participants
were paid a small fee for taking part.

\section{Materials and Design}

All instructions and stimuli were presented to participants using custom-built software running on an Apple Macintosh LC computer. There were 18 experimental stimuli and 22 filler stimuli. Of the 22 filler items, 4 were presented in the encoding phase, 2 before and 2 after the experimental stimuli. The remaining 18 fillers were presented as the first items in the test phase. Experimental stimuli were randomly divided into three equal sets. Order within each stimulus set was randomized and retained for each encoding phase presentation. Each experimental stimulus was represented in four different encoding phase formats, which were as follows.

Environmental-sound format. Eighteen sounds were taken from a pool of sound effects collated by Stuart and Jones (1995); these included sounds produced by various types of transport, sounds of nature, and common household objects. Examples include the sound of a ticking clock and the lowing of a cow. Each sound had been digitized at a sampling rate of $22 \mathrm{kHz}$ and edited to a duration of $8 \mathrm{sec}$. The sounds were stored as resources in the computer that could be accessed from within the program. All sounds were presented to participants over a pair of Technics Digital Monitor stereo headphones.

Spoken-word format. Eighteen nouns that labeled the source of each experimental sound were spoken by the experimenter and individually digitized with a Farallon MacRecorder Voice Digitizer at a sampling rate of $22 \mathrm{kHz}$. These labels had been previously assigned by at least 5 of a set of 6 pilot subjects to name the source of each of the environmental sounds (Stuart \& Jones, 1995). Labels for the sound examples described above were clock and cow. These spoken words were presented to participants through a pair of Technics Digital Monitor stereo headphones.

Written-word format. The 18 experimental nouns described above were presented in the center of the computer monitor in 35 point bold SWA Dutch font.

Written-description format. Stimuli were presented as two lines of descriptive text that included as many references to the sound-producing events associated with the stimulus object as possible. Onomatopoeic words were also included whenever feasible. For example, the following lines of text were used to represent the stimulus horse: $A$ series of whinnies is followed by a neigh. There is a clip-clop as iron shoes walk over concrete. Each printed description was printed in lowercase 18-point SWA Dutch font and presented in the center of the screen. For each encoding phase presentation, two fillers were presented before and two after the experimental stimuli. Aithough the same fillers were used for all participants, the form of the fillers was consistent with the form of the adjacent experimental stimuli.

The mixed design included one between-subjects factor, instruction, with three levels: image, hear, and see. This manipulation rep- resented the type of instructions presented to participants for the treatment of encoding phase stimuli. Twenty-four participants were assigned to each between-subjects condition. There was also a within-subject factor, form, composed of three levels: word, sound, and control. Each of these conditions referred to the encoding phase status of the test phase stimuli. Stimuli in the control condition had not been presented in the encoding phase in any format. It should be pointed out that the stimulus formats described earlier were not necessarily synonymous with the form conditions, since the form of each stimulus was determined by the way in which the stimulus had been processed by the participant. Encoding phase presentation of stimulus sets was blocked and the design was such that each of the three stimulus sets appeared equally often in each form condition. The order of encoding phase form condition presentation was counterbalanced within each participant group.

The format of the stimuli presented, and the instructions for their treatment, varied according to the group to which the participant had been assigned. The presentation format for stimuli in each of the between-subjects instruction conditions is described below. In all instances, and in order to add some apparent meaning to the encoding tasks, participants were required to rate each stimulus on a scale of 1 to 5 . The exact criteria for rating was determined by the condition.

Image instructions. In both the word and the sound form conditions, participants were presented with stimuli in the written-word format. In the former condition, participants were required to imagine that the word was being spoken, and in the latter, they were asked to create an image of the characteristic sound of the word's referent. In each case, the participants were required to rate the ease with which they were able to create the auditory image.

Hear instructions. Stimuli were presented in the spoken-word format and the environmental-sound format in the word and sound conditions, respectively. In both instances, participants rated the ease with which they were able to identify each stimulus.

See instructions. In the word condition, participants were required to identify a stimulus presented in the written-word format and to rate it in terms of its identifiability. In the sound condition, included for the sake of completeness, stimuli were presented in the writtendescription format. The task of participants was to identify the target noun from the auditory scene description and to rate the ease with which they were able to perform this task.

The test phase materials constituted the complete set of 18 experimental spoken words. Each spoken word had been mixed with a background of white noise. In preparing the test stimuli, the intensity of the white noise had been kept constant while the intensity of the spoken word had been altered so that each word was correctly identified by no more than half of a group of 6 pilot subjects (see Stuart \& Jones, 1995). The same procedure was used to generate the 18 test phase filler words, also embedded in a background of white noise. The form condition of each experimental test phase stimulus (word, sound, or control) indicated the form in which the stimulus had originally been processed in the encoding phase.

\section{Procedure}

In the first phase of the experiment, participants were given instructions specific to their particular participant group. The procedures for each between-subjects condition are described below.

Image condition. Participants were told that they would be presented with two sets of words, each of which would appear in the center of the screen. Before each set, they were told that there would be an instruction either to imagine that they could hear the word being spoken aloud, or that they could hear the characteristic sound made by the referent object. A series of 12 words was displayed in the central position of the screen and remained for $8 \mathrm{sec}$. During this time, participants were required to form one of two types of auditory image depending on the specific encoding instructions. A warning beep was then sounded to the participants via the headphones, and a message appeared on the scrcen asking them to record their rating. The message remained on the screen for $5 \mathrm{sec}$, during which period 
participants were required to record their responses. The procedure for both form conditions in the encoding phase was the same.

Hear condition. This condition differed from the image condition only in that participants actually heard either the spoken words or the environmental sounds, rather than being asked to create an image. There was an 8-sec interval between the onset of each auditory stimulus and the instruction to rate the stimulus identifiability.

See condition. Participants read the stimuli presented in either the written-word or written-description format without any instruction to create an image. As in the image condition, the presentation of each stimulus was preceded by a warning beep, and each stimulus remained on the screen for $8 \mathrm{sec}$. Stimuli in the printed-word format were rated in terms of their legibility, and participants were asked to say how easily they were able to identify the object responsible for producing the sounds described by the written description presented in the sound condition. To illustrate and clarify this design, the encoding phase format of stimuli is tabulated in Figure 1.

Each encoding phase, which lasted approximately $5 \mathrm{~min}$, was followed by a few minutes during which the experimenter set up the second phase of the experiment and participants read through the test phase instructions. In the test phase, participants had to identify the 18 noise-embedded filler words followed by the complete set of 18 experimental words, also embedded in a background of white noise. The onset of each test word was automatic, with a 4-sec interstimulus interval (ISI). Participants identified and wrote down each word. The test phase was the same for all participants, regardless of the condition under which they had performed during the encoding phase. On completion of the experiment, participants were fully debriefed

\section{Results and Discussion}

The data were entered into a $3 \times 3$ mixed factorial analysis of variance (ANOVA) comprising one between-subjects factor, instruction (image vs. hear vs. see), and one withinsubject factor, form (word vs. sound vs. control). Mean scores, expressed as a proportion of the total number of words in each condition, are presented in parentheses. The superior performance of participants in both image $(40.05 \%)$ and hear $(41.90 \%)$ conditions, over those in the see condition $(33.10 \%)$, resulted in a significant main ef-

\begin{tabular}{|c|c|c|c|}
\hline & \multicolumn{2}{|c|}{ Encoding Phase Stimulus Form } \\
\hline & & Word & Sound \\
\hline \multirow{3}{*}{ 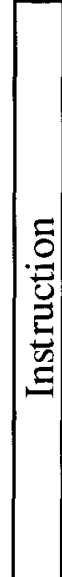 } & 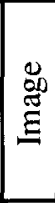 & $\begin{array}{l}\text { Stimuli in printed- } \\
\text { word format. } \\
\text { Participants imagine } \\
\text { hearing each as a } \\
\text { spoken word. }\end{array}$ & $\begin{array}{l}\text { Stimuli in printed- } \\
\text { word format. } \\
\text { Participants imagine } \\
\text { hearing referent } \\
\text { sound of each word. }\end{array}$ \\
\hline & 氞 & $\begin{array}{l}\text { Stimuli in spoken- } \\
\text { word format. } \\
\text { Participants listen } \\
\text { to each word. }\end{array}$ & $\begin{array}{l}\text { Stimuli in } \\
\text { environmental-sound } \\
\text { format. } \\
\text { Participants identify } \\
\text { each sound. }\end{array}$ \\
\hline & $\ddot{\varkappa}$ & $\begin{array}{l}\text { Stimuli in printed- } \\
\text { word format. } \\
\text { Participants read } \\
\text { each word. }\end{array}$ & $\begin{array}{l}\text { Stimuli in written- } \\
\text { description format. } \\
\text { Participants identify } \\
\text { each sound source. }\end{array}$ \\
\hline
\end{tabular}

Figure 1. Experiment 1, format of stimuli presented and type of participant encoding for each encoding phase condition. Stimuli in the control condition appeared only in the test phase. fect of instruction $\left[F(2,69)=4.42, M S_{\mathrm{e}}=1.26, p<.05\right]$. Planned pairwise means comparisons showed that only the differences in performance between the image versus see and hear versus see conditions reached significance $\left[F(1,69)=4.96, M S_{\mathrm{e}}=1.26, p<.05\right.$, and $F(1,69)=7.96$, $M S_{\mathrm{e}}=1.26, p<.01$, respectively]. Because the difference in performance between the image versus hear conditions failed to reach significance $(F<1)$, it is suggested that overall, images facilitated performance at the same level as did perceived stimuli.

Due to the between-subjects design, it was possible to analyze the interactions between form and the pairwise means comparisons. Two of these interactions were significant, image versus see $\left[F(2,138)=4.84, M S_{\mathrm{e}}=1.09, p<\right.$ $.01]$ and hear versus see $\left[F(2,138)=4.96, M S_{e}=1.09\right.$, $p<.01]$. An examination of Figure 2 suggests that both these interactions were due to the facilitatory effect of processing the stimuli as auditory rather than visual stimuli. The fact that stimuli in the image condition were presented visually seems to have had no significant detrimental effect on the results. The baseline level of performance under see instructions for printed words is consistent with that of at least one other study, which failed to show any significant cross-modal priming between written and spoken words (Gipson, 1986).

Presentation of stimuli in the word form (46.30\%) produced more facilitation than presentation in either sound form $(35.65 \%)$ or control $(33.10 \%)$. This difference was supported by a significant main effect of form $[F(2,138)=$ $11.70, M S_{\mathrm{e}}=1.09, p=.01$ ]. Planned comparisons between the word versus control and word versus sound were both significant at the $p<.01$ level $[F(1,138)=20.79$, $M S_{\mathrm{e}}=1.09$, and $F(1,138)=13.54, M S_{\mathrm{e}}=1.09$, respectively]. These results can be attributed to the superior identification performance for word stimuli that had been encoded under both image and hear instructions. The lack of a significant difference between the sound and control conditions suggests that there was no reliable cross-form transfer between stimuli processed as sounds and the identification of spoken words. Finally, there was a significant interaction between form and instruction $[F(4,138)=3.27$, $\left.M S_{\mathrm{e}}=1.09, p<.05\right]$, reflecting the fact that identification of stimuli encoded in the word form was superior to identification of stimuli encoded in the other two conditions, but only under hear and image instructions.

The clear pattern to emerge from these results is that creating the image of a spoken word is sufficient to facilitate the identification of that word in a later presentation. Although creation of an auditory image of the referent sound resulted in a numerical advantage for subsequent identification, this advantage did not approach an acceptable level of significance. The nonsignificant advantage for identification of stimuli in the nonverbal image condition is interesting since Durgunoğlu and Roediger (1987) also showed a nonsignificant advantage when printed stimuli were preceded by an image of the referent picture. In our experiment, this nonsignificant advantage was matched by an equally small advantage for perceived sounds presented under hear instructions. 


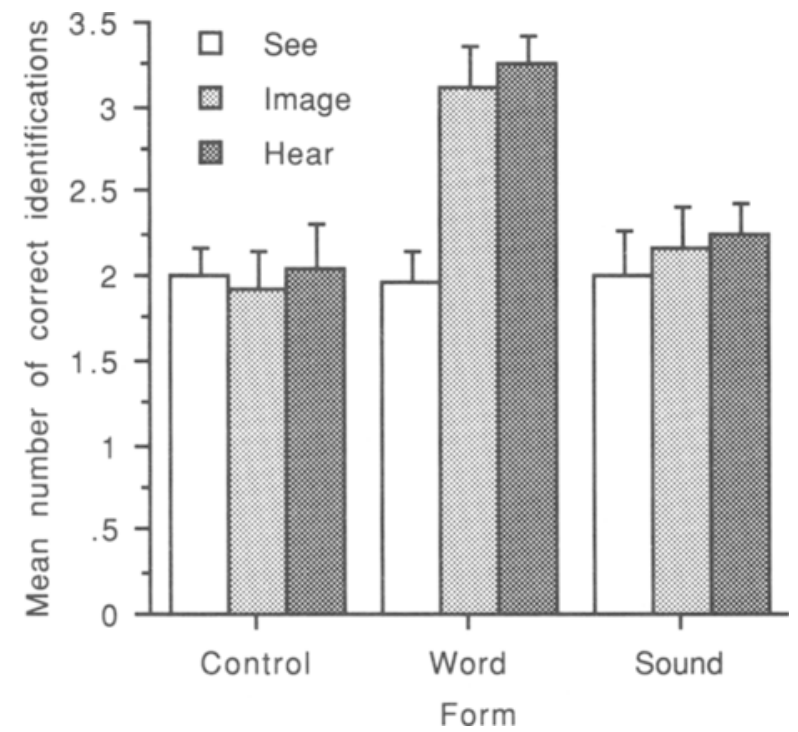

Figure 2. Experiment 1, mean number of words correctly identified in each condition, with standard error bars.

Having discovered that the creation of the auditory image of a spoken word was sufficient to significantly facilitate performance in the identification of a spoken-word percept, we were interested to see if this imaginal priming effect was limited to the identification of verbal stimuli. In view of Stuart and Jones's (1995) demonstration of a nonverbal repetition priming effect for auditorily presented nonverbal stimuli, Experiment 2 was designed to test the effect of processing nonverbal auditory images on the identification of nonverbal auditory percepts.

\section{EXPERIMENT 2}

The theme of imaginal priming within the auditory modality was extended with the specific aim of investigating the transfer between nonverbal images and percepts. Once again, a between-subjects design was used in order to eliminate any contamination from unsolicited imaging. Two groups of subjects were presented with auditory stimuli in each of two formats, environmental sounds and spoken words. Participants in both groups were required to listen to and rate the identifiability of the stimuli presented in the environmental-sound format. The treatment of stimuli presented in the spoken-word format depended on the instructions given to each between-subjects group. While one subject group listened to and identified each spoken word, members of the other group were instructed to create an auditory image of the referent sound of each auditorily presented noun. Members of both groups then took part in the same test of perceptual identification in which they were required to identify a series of attenuated nonverbal sounds, each presented with a method of ascending limits. Test phase sounds were related to the encoding phase stimuli in one of three ways: Either the sounds had been presented before in the encoding phase, an auditory image of the sound had been created during the encoding phase, or the spoken word that labeled the source of the sound had been presented before without any instructions to form an auditory image.

\section{Method}

\section{Subjects}

Thirty-six undergraduate participants took part on a voluntary basis. All spoke English as their first language and all reported normal hearing. None of the participants had taken part in Experiment 1.

\section{Materials and Design}

As in Experiment 1, instructions and stimuli were presented to participants using custom-built software on an Apple Macintosh LC computer, played through a pair of Technics Digital Monitor stereo headphones. All experimental stimuli were stored in each of two stimulus formats:

Environmental-sound format. Twenty-four digitized experimental sounds and two filler sounds, taken from the same pool as those used in Experiment 1, were stored as resources in the computer.

Spoken-word format. Twenty-four spoken nouns that labeled the experimental sound sources, together with four filler nouns, all sampled at a rate of $22 \mathrm{kHz}$, were also stored.

The 24 experimental stimuli were randomly divided into three sets of eight. Presentation order of stimuli within each set was also randomized and the order was preserved for each encoding phase presentation. Participants were divided into two groups. There was one between-subjects factor of instruction, which consisted of two levels: image and hear. There was also a within-subject factor, form, which consisted of three levels: word, sound, and control. The form condition indicated the encoding phase presentation format of the experimental stimuli. Control stimuli had not been studied and were presented for the first time at test. The instruction condition indicated the manner in which those encoding phase stimuli presented in the spokenword form had been processed by participants. For each betweensubjects group, two blocks of encoding phase stimuli were presented, one in spoken-word format and the other in the environmental-sound format. The only manipulation between groups was the instruction for the treatment of stimuli presented in the word form condition, which was as follows:

Image instructions. Participants were presented with a block of stimuli in the spoken-word format and instructed to create an auditory image of each word's referent sound.

Hear instructions. Participants were presented with a block of stimuli in the spoken-word format and were instructed only to listen to and identify each word.

The remaining encoding phase form condition, sound, was identical for each between-subjects instruction group. Participants were presented with and asked to identify stimuli presented in the environmental-sound format. Control stimuli appeared in the test phase of the experiment, but not at study. The presentation format and participant processing instructions for encoding phase stimuli are tabulated in Figure 3.

The distribution and order of stimuli in each between-subjects group were identical. Each encoding phase was preceded and followed by two filler nouns, bringing the total number of items presented to 12. Participants treated these filler nouns as they had treated experimental stimuli presented in the spoken-word format.

The test phase items consisted of the complete set of experimental stimuli, presented in the environmental-sound format, preceded by two filler sounds. The loudness of each test phase sound was attenuated using a Marconi TF 2160 step attenuator. Participant groups, word sets, and conditions were all counterbalanced in a Latin square design. All 24 experimental sounds appeared in the test phase: The order of presentation of these sounds was first randomized and then preserved for all participants. 


\begin{tabular}{|c|c|c|c|}
\hline & \multicolumn{2}{|c|}{ Encoding Phase Stimulus Form } \\
\hline & & Environmental Sound & Spoken Word \\
\hline \multirow{2}{*}{ | } & & $\begin{array}{l}\text { Stimuli in } \\
\text { environmental sound } \\
\text { format. } \\
\text { Participants identify } \\
\text { each sound source. }\end{array}$ & $\begin{array}{l}\text { Stimuli in spoken- } \\
\text { word format. } \\
\text { Participants } \\
\text { identify each word. }\end{array}$ \\
\hline & : & $\begin{array}{l}\text { Stimuli in } \\
\text { environmental } \\
\text { sound format. } \\
\text { Participants identify } \\
\text { each sound source. }\end{array}$ & $\begin{array}{l}\text { Stimuli in spoken- } \\
\text { word format. } \\
\text { Participants imagine } \\
\text { hearing referent } \\
\text { sound of each word. }\end{array}$ \\
\hline
\end{tabular}

Figure 3. Experiment 2, format of stimuli presented and type of participant encoding for each encoding phase condition. Stimuli in the control condition appeared only in the test phase.

\section{Procedure}

Participants were informed that they would be taking part in two experiments involving spoken-word processing and environmentalsound identification. The encoding phase was presented to participants as in the first experiment: Treatment of the stimuli presented in the environmental-sound format was identical for both instruction conditions, with participants being asked to name the source of each presented sound. The treatment of stimuli presented in the spokenword format differed between participant groups. Under image instructions, participants were told that for each presentation of a spoken word, they were required to listen and then form an auditory image of the sound associated with the object named by that word. Participants were given as much time as they required to form the appropriate image; however, all took less than $10 \mathrm{sec}$. Under hear in structions, subjects were simply required to listen to each word. By way of making the hypothesis less transparent, participants were asked to rate the ease of "audiolization" or identification of each image or sound on a 5-point scale. The encoding phase, which took approximately $5 \mathrm{~min}$ to complete, was followed by a few minutes during which the experimenter set up the experimental apparatus and the participants read the test phase instructions.

The participants were told that they would be taking part in another experiment that was intended to determine how easy or difficult different sounds were to identify. The loudness of each sound was initially attenuated by $65 \mathrm{~dB}$ (a point found to be well below hearing threshold) and presented to the participants. If the participant was unable to accurately identify the sound, the level of attenuation was reduced by $5 \mathrm{~dB}$ and the sound was replayed. This process was repeated until the participant was able to identify the sound source correctly. The level of attenuation at which correct identification occurred was recorded for each sound (this technique was first used by Stuart \& Jones, 1995). After participants completed the test phase, they were given a full description of the aims and purpose of the experiment.

\section{Results and Discussion}

The results are presented graphically in Figure 4. Data presented in the text are expressed in terms of the mean level of attenuation $(\mathrm{dB})$ at which participants were able to identify the sound. The data were subjected to a two-way mixed ANOVA with one between-subjects factor, instruction (hear vs. image), and one within-subject factor, form (word vs. sound vs. control). There was a significant main effect of form $\left[F(2,68)=23.8, M S_{\mathrm{e}}=7.89, p=.01\right]$. Planned means comparisons were conducted, which con- firmed that performance in the sound condition $(34.38 \mathrm{~dB})$ was significantly better than performance in both the word condition $(31.32 \mathrm{~dB})\left[F(1,68)=21.2, M S_{\mathrm{e}}=7.89, p=\right.$ $.01]$ and the control condition $(29.9 \mathrm{~dB})[F(1,68)=45.77$, $\left.M S_{\mathrm{e}}=7.89, p=.01\right]$. Somewhat surprisingly, neither the main effect of instruction $(F<1)$, nor the form $\times$ instruction interaction $\left[F(2,68)=2.53, M S_{\mathrm{e}}=7.89, p=.09\right]$ were statistically significant. Although a significant result in either or both of these effects would have been a strong indicator of a facilitation effect following an imaginal prime, there are a number of reasons why the present results need not necessarily lead to the opposite conclusion.

In both participant groups, presentation of stimuli in the sound and control conditions was identical and only treatment of the word condition was manipulated between participants. For this reason, one would not expect any betweensubjects difference in the sound and control conditions. Any differential effect of instructions on the word stimulus form would be offset by the expected lack of effect on the other two stimulus form conditions. A similar argument might be applied to the form $\times$ instruction interaction, which just failed to reach a customary level of significance. An interaction involving the word condition would have been weakened by the expected null interaction effect between the other two conditions. For this reason, it was decided to perform a separate analysis on the data for participants in the image group. The data were analyzed in a one-way ANOVA with stimulus format (image vs. sound vs. control) as the single within-subject factor. As expected, there was a significant main effect of stimulus format $\left[F(2,34)=13.53, M S_{\mathrm{e}}=6.36, p=.01\right]$. Pairwise means comparisons indicated that performance in both the sound $(34.72 \mathrm{~dB})$ and image $(33.02 \mathrm{~dB})$ conditions was facilitated with respect to baseline performance $(30.38 \mathrm{~dB})[F(1,34)=$

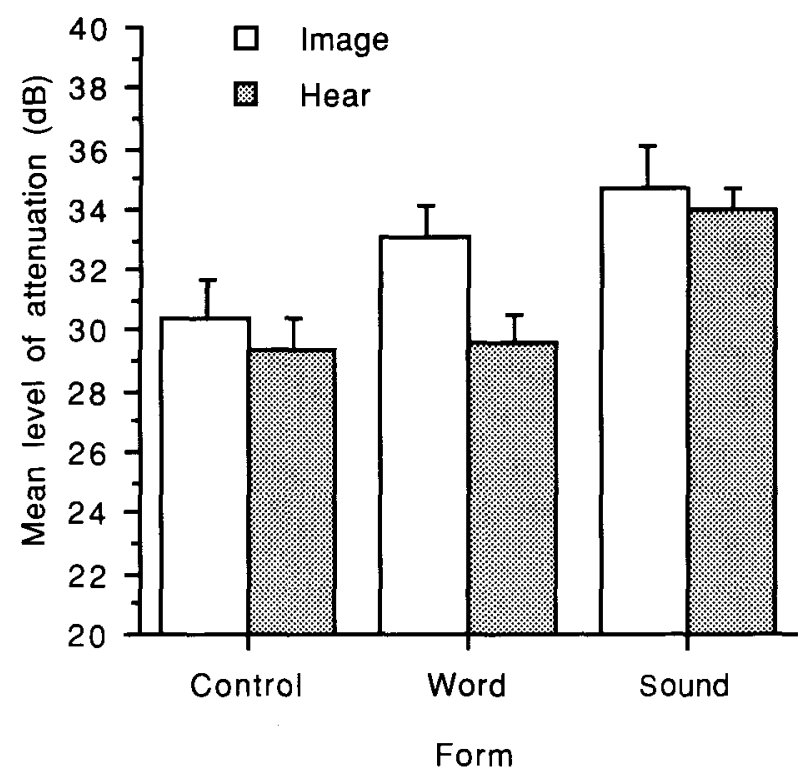

Figure 4. Experiment 2, mean level of attenuation (dB) at which correct identification occurred, with standard error bars. 
$26.64, M S_{\mathrm{e}}=6.36, p=.01$, and $F(1,34)=9.85, M S_{\mathrm{e}}=$ $6.36, p<.01$, respectively]. The difference between sound and image just failed to reach significance at the $p<.05$ level $\left[F(1,34)=4.09, M S_{\mathrm{e}}=6.36, p=.051\right]$.

The results clearly show that asking participants to image an environmental sound specified by a single spoken word can have the same facilitative effect in a subsequent identification task as actually hearing an externally presented sound. The better performance in perceived-sound primes compared with that in the imaged-sound primes is consistent with the nonsignificant advantage of same-sound priming over similar-sound priming (using a similar sound from a different sound source) found by Stuart and Jones (1995). A more detailed discussion of the possible significance of this finding is presented in the next section.

\section{GENERAL DISCUSSION}

Two experiments were used to investigate the extent to which processing an internally generated stimulus would facilitate the identification of a physically presented stimulus. These experiments differed from previous imagery experiments in a number of ways; in the first instance, they were based on an implicit, rather than an explicit, memory paradigm; the focus of these experiments was on auditory, rather than visual, images and percepts; and finally, the effectiveness of images in facilitating nonverbal as well as verbal targets was investigated. It was found that processing an auditory image would facilitate the subsequent identification of the corresponding percept, but only when the image and percept were in the same form: Creation of an environmental-sound image resulted in the facilitation of an environmental-sound stimulus, and creation of a spoken-word image facilitated the identification of a spoken word. Creation of an environmental-sound image did not facilitate the identification of a spoken word.

In the first experiment, the hypothesis that generating imaginal stimuli would facilitate the identification of perceived stimuli when both target and prime were in the form of a spoken word was confirmed. In common with Durgunogglu and Roediger (1987), it was also found that there was no significant transfer between the image of a word's referent and the actual word. These results do, however, contradict the findings of Basden et al. (1994), working in the visual modality. In explaining why other experimenters had failed to obtain significant transfer from an imagined referent prime, Basden et al. suggested that the use of a random mixed (read and imaged) stimulus design might have discouraged participants from using a conceptual encoding strategy that otherwise might have given rise to a residual priming effect in the data-driven test (see Brown \& Mitchell, 1994). Since a blocked between-subjects design was used in the present experiment, such an argument fails to explain the data presented here, although it should be kept in mind that these arguments were developed in the context of cross-language priming. It is interesting to note that the small numerical advantage for stimuli primed by a referent image was similar to that from actual presentation of the referent sound. Unfortunately, the lack of a comparable perceptual-referent prime in the experiment by Basden et al. makes it difficult to draw further comparisons between the two experiments. The results of Experiment 1 do, however, map on to the data for auditory crossform priming using real stimuli (Stuart \& Jones, 1995).

Transfer between imaged and perceived environmental sounds was investigated in Experiment 2. By creating an environmental-sound image during the encoding phase of an implicit memory experiment, participants were subsequently able to identify a sound from the same category at a higher level of attenuation than when no image had been created. It is interesting to note that the facilitation from an imaginal prime was less than that from preexposure to a perceived stimulus, a difference that approached statistical significance. This result represents a partial replication of the nonverbal auditory priming effect found by Stuart and Jones (1995). It also shows that within the auditory modality, the necessary conditions for transfer of nonverbal stimuli need not involve the processing of a physical copy of the prime stimulus.

These results may be explained by adopting Roediger's (1992) contention that the formation of the auditory image engages the same central perceptual processes that would be involved in actually perceiving the sound or word, a view that has received a degree of support among researchers of mental imagery (see Finke, 1985, for a review). According to many theories of implicit memory, most notably the TAP approach, the greater the degree of similarity between the prime and target stimuli, the greater the degree of transfer. One problem to arise from this issue of similarity is the question of how an unrestricted image can be similar enough to a specific percept that there is no difference in the degree of priming. In the absence of any instructions to create an image with any particular voicing attributes or auditory characteristics, it is unlikely that the participant would spontaneously choose to image in a voice that matched the one presented in the test. Less likely still is the idea that the participant would imagine a sound that was identical to the one presented in the test phase of Experiment 2.

The current status of specificity in spoken-word priming is equivocal, with data both supporting (Biederman \& Cooper, 1991; Kinoshita \& Wayland, 1993; Rajaram \& Roediger, 1993; Schacter \& Church, 1992) and refuting (Brown \& Carr, 1993; Graf \& Ryan, 1990; Jacoby \& Hayman, 1987; Srinivas, 1993) a stimulus-specific view of transfer. In the experiment by Roediger et al. (1992), priming between an imaged visual word and a perceived visual word was limited to the level found between real words with mismatched typographies, thus supporting the application of stimulus-specific transfer to imaginal priming. On the other hand, as has already been stated, imaginal primes in the present experiment were able to facilitate real percepts at the same level as those that had been exact repetitions of the encoded prime. An interesting perspective on this dilemma has been provided by Schacter and Church (Church \& Schacter, 1994; Schacter, 1992; Schacter \& Church, 1992; Schacter, Church, \& Osowiecki, 1994). Although Schacter and Church were unable to show percep- 
tual transfer specificity in a perceptual identification task, using words embedded in white noise, they were able to show specificity on an auditory word stem completion task. Their results led them to conclude that in some way, the white noise mask was responsible for the lack of voice specificity. That white noise masking was used in the word identification task in the present experiment may explain how an imaged voice was as able to facilitate word identification as was a spoken-word stimulus. An alternative explanation, assuming that participants created spokenword images in their own internal voices, is that one's "inner voice" is neutral with respect to transfer. This appears to be the case with explicit transfer, as was the conclusion of Geiselman (Geiselman \& Bjork, 1980; Geiselman \& Glenny, 1977), who found that recognition memory was better for words imaged and presented in the same voice than for words imaged and presented in different voices. When asked to image in their own voice, participants' performance was better than that in the different voice condition, a finding that may indicate that the inner voice has a more direct access to an abstract lexical store.

Insofar as the difference between priming from imaged sounds and perceived sounds approached an acceptable level of significance, Experiment 2 poses less of a problem to the transfer specificity principle. Although the sounds presented in Experiment 2 were all considered to be stereotypical exemplars, it is still necessary to accept that participants created an image similar enough to the test sound to significantly facilitate subsequent sound identification. In a nonverbal priming experiment, Stuart and Jones (1995) found no significant advantage in facilitation for sounds primed by prior presentation of the same sound over sounds primed by prior presentation of a similar sound from the same type of sound source. There was, however, a small, nonsignificant advantage in favor of stimulus-specific priming. A comparison of the results of Experiments 1 and 2 may provide a clue to explaining the problem of transfer specificity. Given that more constraints must necessarily be placed on spoken-word images over environmental-sound images, it might be expected that there would be more chance of a positive match between the spoken-word image and the actual spoken word. Since environmental sounds are much less constrained, an exact match is much less likely.

In conclusion, the data presented here demonstrate an interesting parallel in the facilitative effects of both real and imaginal primes on the subsequent perceptual identification of auditory stimuli.

\section{REFERENCES}

Basden, B. H., Bonilla-Meeks, J. L., \& Basden, D. R. (1994). Crosslanguage priming in word-fragment completion. Journal of Memory \& Language, 33, 69-82.

BIEDERMAN, I., \& COOPER, E. E. (1991). Evidence for complete transitional and reflectional invariance in visual object priming. Perception, 20, 585-593.

BLAXTON, T. A. (1989). Investigating dissociations among memory measures: Support for a Transfer Appropriate Processing framework. Journal of Experimental Psychology: Learning, Memory, \& Cognition, 15 , 657-668.
Brown, A. S., \& Mitchell, D. B. (1994). A reevaluation of semantic versus nonsemantic processing in implicit memory. Memory \& Cognition, 22, 533-541.

BROWN, J. S., \& CARR, T. H. (1993). Limits on perceptual abstraction in reading: Asymmetric transfer between surface forms differing in typicality. Journal of Experimental Psychology: Learning, Memory, \& Cognition, 19, 1277-1296.

Church, B. A., \& SChacter, D. L. (1994). Perceptual specificity of auditory priming: Implicit memory for voice intonation and functional frequency. Journal of Experimental Psychology: Learning, Memory, \& Cognition, 20, 521-533.

DurgunoǦlu, A. Y., \& RoEdiger, H. L., III (1987). Test differences in accessing bilingual memory. Journal of Memory \& Language, 26, 377 391.

Farah, M. J., \& Sмith, A. F. (1983). Perceptual interference and facilitation with auditory imagery. Perception \& Psychophysics, 33, 475-478.

FINKE, R. A. (1985). Theories relating mental imagery to perception. Psychological Bulletin, 98, 236-259.

Geiselman, R. E., \& BJoRK, R. A. (1980). Primary versus secondary rehearsal in imagined voices: Differential effects on recognition. Cognitive Psychology, 12, 188-205.

GeISELMAN, R. E., \& GlenNY, J. (1977). Effects of imagining speakers' voices on the retention of words presented visually. Memory \& Cognition, 5, 499-504.

GIPSON, P. (1986). The production of phonology and auditory priming. British Journal of Psychology, 77, 359-375.

Graf, P., \& Ryan, L. (1990). Transfer-appropriate processing for implicit and explicit memory. Journal of Experimental Psychology: Learning, Memory, \& Cognition, 16, 978-992.

JACOBY, L. L., \& HAYMAN, C. A. G. (1987). Specific visual transfer in word identification. Journal of Experimental Psychology: Learning, Memory, \& Cognition, 13, 456-463.

Kinoshita, S., \& WAYLAND, S. V. (1993). Effects of surface features on word-fragment completion in amnesic subjects. American Journal of Psychology, 106, 67-80.

Kolers, P. A., \& Roediger, H. L., III (1984). Procedures of mind. Journal of Verbal Learning \& Verbal Behavior, 23, 425-449.

OKADA, H., \& MATSUOKA, K. (1992). Effects of auditory imagery on the detection of a pure tone in white noise: Experimental evidence of the auditory perky effect. Perceptual \& Motor Skills, 74, 443-448.

Peterson, M. J., \& Graham, S. E. (1974). Visual detection and visual imagery. Journal of Experimental Psychology, 103, 509-514.

RaJARAM, S., \& RoEDiger, H. L., III (1993). Direct comparison of four implicit memory tests. Journal of Experimental Psychology: Learning, Memory, \& Cognition, 19, 765-776.

Richardson-KLavehn, A., Gardiner, J. M., \& JaVa, R. I. (1994). Involuntary conscious memory and the method of opposition. Memory, 2, 1-29.

ROEDIGER, H. L., III (1990). Implicit memory: Retention without remembering. American Psychologist, 45, 1043-1056.

RoEDiger, H. L., III, \& BLAXTON, T. A. (1987). Effects of varying modality, surface features, and retention interval on priming in wordfragment completion. Memory \& Cognition, 15, 379-388.

Roediger, H. L., III, \& SRINIVAS, K. (1993). Specificity of operations in perceptual priming. In P. Graf \& M. E. J. Masson (Eds.), Implicit memory: New directions in cognition, development, and neuropsychology (pp. 17-48). Hillside, NJ: Erlbaum.

Roediger, H. L., III, Weldon, M. S., \& Challis, B. H. (1989). Explaining dissociations between implicit and explicit measures of retention: A processing account. In H. L. Roediger III \& F. I. M. Craik (Eds.), Varieties of memory and consciousness: Essays in honour of Endel Tulving (pp. 3-41). London: Erlbaum.

Roediger, H. L., III, Weldon, M. S., STADler, M. L., \& Riegler, G. L. (1992). Direct comparison of two implicit memory tests: Word fragment and word stem completion. Journal of Experimental Psychology: Learning, Memory, \& Cognition, 18, 1251-1269.

SCHACTER, D. L. (1992). Priming and multiple memory systems: Perceptual mechanisms of implicit memory. Journal of Cognitive Neuroscience, 4, 244-256.

SChacter, D. L., Bowers, J., \& BoOKer, J. (1989). Intention, awareness, and implicit memory: The retrieval intentionality criterion. In 
S. Lewandowsky, J. C. Dunn, \& K. Kirsner (Eds.), Implicit memory: Theoretical issues (pp.47-65). London: Erlbaum.

SCHACter, D. L., \& CHURCH, B. A. (1992). Auditory priming: Implicit and explicit memory for words and voices. Journal of Experimental Psychology: Learning, Memory, \& Cognition, 18, 915-930.

Schacter, D. L., Church, B. A., \& Osowiecki, D. M. (1994). Auditory priming in elderly adults: Impairment of voice-specific implicit memory. Memory, 2, 295-323.

SNODGRASS, J. G., \& HirSham, E. (1994). Dissociations among implicit and explicit memory tasks: The role of stimulus similarity. Journal of Experimental Psychology: Learning, Memory, \& Cognition, 20 , 150-160.
SRINIVAS, K. (1993). Perceptual specificity in nonverbal priming. Journal of Experimental Psychology: Learning, Memory, \& Cognition, 19, $582-602$.

Stuart, G. P., \& Jones, D. M. (1995). Priming the identification of environmental sounds. Quarterly Journal of Experimental Psychology, 48A, 741-761.

Weldon, M. S., \& Jackson-BarRetT, J. L. (1993). Why do pictures produce priming on the word-fragment completion test? A study of encoding and retrieval factors. Memory \& Cognition, 21, 519-528.

(Manuscript received December 9, 1994; revision accepted for publication April 27, 1995.) 